\title{
A Novel Predict Corrosion Rate Model Based on RBFNN
}

\author{
Mohammed Hliyil Hafiz \\ Department of Production and Metallurgy Engineering, University of Technology, Baghdad, Iraq
}

\begin{abstract}
Predication Corrosion rate is quantitative method by which the effectiveness of corrosion control and prevention techniques can be evaluated and provides the feedback to enable corrosion control and prevention methods to be optimized. In this paper, a novel Model to predict corrosion rate based on RBFNN was proposed. A model is produced from experimental work for one year and eighty four specimens were used through this work using anode with a high level of precision. Learning data was performed by using a 36 samples test with different Environment Resistivity (ER), Impressed Current (IC), Location of Anode (LA), Corrosion Current (CC) and Corrosion Rate (CR). The RBFNN model has five input nodes representing the (ER, IC, CC, LN, and SA), sixteen nodes at hidden layer and one output node representing corrosion rate (CR). Simulation test use 6 data samples taken from the experimental results to check the performance of the neural network on these data and shows the proposed model can be use successfully to predicate the corrosion rate.
\end{abstract}

Keywords: Corrosion, Corrosion rate, RBFNN

\section{Introduction}

Corrosion control modeling has become integral component of the modern science and researching of complex systems. The massive introduction of Artificial Intelligent (AI) in the workplace has also drastically changed daily operations. Artificial Intelligent play important roles in data acquisition in laboratory and field environments, data processing and analysis, data searching and data presentation in understandable and useful formats(H M G Smets, W F L Bogaerts. 1992).

Much researcher focus on Artificial neural network had been applied in studies of other corrosion fields for several years (H M G Smets, W F L Bogaerts. 1992)(H M G Smets, W F L Bogaerts. 1992)(Y Cheng, W L Huang, C Y Zhou. 1999)(J Leifer, P E Zapp, J I Michalonis. 1999)(J Leifer, J I Mickalonis. 2000)(F H Haynie, J P Upham. 1971)(Jianping Cai, Wei Ke. 1997)(Xiaoyan Ma, Yanbing Luan, Zuyu Qu, et al.. 2001), there is few application in corrosion in seawater. In (Satoshi Kibata, Hisayoshi Matsuyama, and Shigeyuki Tateno, 2009) a new study to know corrosion wastages from outside surface of pipes by estimating a corrosion rate in order to select pipes to be checked. To achieve the purpose, corrosion rates based on corrosion cases are estimated by using the database modeling method. In (Takako Kuroda, Ryuzo Takai, Yuki Kobayashi, Yoshiteru Tanaka and Shoichi Hara, 2008) study focus on predict the time of oil leaking from shipwrecks due to corrosion. Generally speaking, the corrosion factors are dissolved oxygen, temperature, $\mathrm{pH}$, salinity, current velocity, wave action, marine growth, bacteria and so on. The corrosion factors, which are the influence of immersion time, dissolved oxygen, temperature and water pressure on corrosion under the sea, are clarified by the results of laboratory experiments. The immersion test and polarization resistance test in high pressure tank for the hull structural specimen were carried out. In (Wei You, Yaxiu Liu, 2008) an artificial neural network applied software, the authors developed artificial neural network to predict the corrosion rate of materials in sea water. Moreover, the model was used to analyze the quantitative effects of environment factors of sea water on the corrosion rate.

In this paper, artificial intelligent used for corrosion prevention requires identification of corrosion rate that gives the full corrosion protection with the presence of certain environment variables was proposed. The RBFNN used to predicate corrosion rate taking the five variables as input and using the practical results data for the learning process. This can be done by creating a mathematical model for the process and choosing the best neural network architecture, decision function and learning algorithm for this application.

\section{Theoretical background}

THE Stern-Geary equation (J. A. Gonzalez, A. Molina, M. L. Escudero, and C. Andrade, 1985) directly relates the impedance of a corroding material (the electrode) to its corrosion rate. Many electrochemical techniques of corrosion rate measurement make use of this relationship to determine the corrosion rate by impedance measurement. In its simpler form, a parallel resistor and capacitor may represent this impedance. When referring to the impedance of an electrode, it is the entire impedance that is being referred to. When referring to resistance, the value of the resistive component is being referred to. The resistance, known as the charge transfer resistance, or, loosely speaking, the polarization resistance, represents the electrode's ability to dissolve into its environment 
low resistances indicate high corrosion rates and high resistances represent low corrosion rates. Standard techniques, such as linear polarization (LP) and electrochemical impedance spectroscopy (EIS) (D. A. Jones, Principles and Prevention of Corrosion, 1992), measure the resistance and impedance, respectively, by applying small voltage signals to the electrode and then observing the current response.

\subsection{Corrosion Rate with Impressed Current}

The system was investigated as a function of environment resistivity, impressed current, location of anode, corrosion rate, corrosion current and corrosion potential. From measuring the weight loss one can calculate the corrosion current value and corrosion rate value according to Faraday's law.

$$
i_{\text {coor }}=\frac{\triangle W \cdot n \cdot F}{M t \cdot A \cdot t} * 10^{6}
$$

where:

$i=$ corrosion current density, $\mu \mathrm{A} / \mathrm{cm}^{2}$

$\Delta W=$ weight loss, $\mathrm{g}$

$n=$ number of electrons

$F=$ Faraday's number $=96487 \mathrm{C} / \mathrm{g}$ eq.

$M t=$ molecular weight of metal $(\mathrm{Fe}=55.847 \mathrm{~g} / \mathrm{mol})$

$t=$ exposure time, $\mathrm{s}$

$A=$ surface area of metal specimen, $\mathrm{cm}^{2}$

\section{The proposed method}

\subsection{Experimental Procedure}

Anode was placed so that all major pipelines would receive protection current whenever the impressed current system was off. After switching on the electrical circuit and the distribution of both anode and impressed current as cathodic protection, current density, distance between cathode and anode, environment resistivity and voltage of power supply.

In order to obtain the effects of the studied parameters the impressed current anode was located in the middle and in the end of the cathode according to surface areas 832.1 and $1863.9 \mathrm{~cm} 2$ in different states (bare and coated) and current demands. The anode has been located away from the cathode as shown in Figure 1. A remote anode is not able to protect an unlimited pipe size.

\subsection{RBFNN Model for Cathodic Protection}

From the examples ANN captures the domain knowledge(De la Mata-Moya, D.; Jarabo-Amores, P.; Rosa-Zurera, M.; Vicen-Bueno, R.; Nieto-Borge, J.C.; 2007). ANN can handle continuous as well as discrete data and have good generalization capability as with fuzzy expert systems. An ANN is a computational model of the brain. They assume that computation is distributed over several simple units called neurons, which are interconnected and operate in parallel thus known as parallel distributed processing systems or connection systems. Implicit knowledge is built into a neural network by training it. Several types of ANN structures and training algorithms have been proposed.

The basic form of RBF architecture involves entirely three different layers. The input layers is made $n$, of source nodes while the second layer is hidden layer of high enough dimension which senses a different purpose from that in a multilayer perception.

The output layer supplies the response of the network to the activation patterns applied to the input layer. The tram formation from the input layer to hidden is nonlinear whereas the transformation from the hidden from unit to the output layer is linear.

The transfer function for a radial basis neuron is:

$\operatorname{radbas}(\mathrm{n})=\mathrm{e}-\mathrm{n} 2$

This function calculates a layer's output from its net input. 
For effective current predicting of cathodic protection, the selection of proper inputs and outputs of ANN, structure of the network and training of it using appropriate data should be done with utmost care. In the present study, inputs are selected as five inputs these are (Environment Resistivity (ER), Impressed Current (IC), Location of Anode (LA), Surface Area (SA), and Corrosion Current (CC)) and it have one output which is the predicted Corrosion Rate (CR).

\section{Results}

The experiment results were used to train the neural network which have been constructed and trained using 36 data samples from the experimental data and six samples were used for generalization test of the trained neural network as shown in table 1.

The third step was the generalization test for the neural network. The generalization test means to test the neural network on data samples other than those data samples used in the learning process and to check the performance of the neural network on these data. In our case, we used six data samples taken from the experimental results for the generalization test. This neural network was simulated using the scientific and engineering package MATALB ${ }^{\circledR} 7.2$.

\section{Discussion}

From the analysis of the results in Table 1, it is observed that the accuracy of the RBFNN method was slightly superior when compared to the experimental on account of mean average error (MAE). Figure 3 shows a plot of experimental against corresponding RBFNN prediction. A linear correlation can be observed and the correlation coefficient was found Table 2 .

\section{Conclusion}

This study introduce a new study of corrosion rate at different conditions based on the Radial Basis Function (RBFNN) has been explored, and this was obvious from the generalization test. The simulation data from experimental test has been used for training and testing. The laboratory test has been carried out to investigate the corrosion rate. The Simulation results show that RBF can be very successively identifying corrosion taking the environment variables (Environment Resistivity (ER), Impressed Current (IC), Location of Anode (LA), Corrosion Current $(\mathrm{CC})$ ). The difference of corrosion rate between prediction and field test is considered almost negligible; this means that it can solve many problems that have been costly and experimental difficulties.

\section{References}

D. A. Jones. (1992). Principles and Prevention of Corrosion, $2^{\text {nd }}$ ed. Englewood Cliffs, NJ: Prentice-Hall, 1992.

De la Mata-Moya, D.; Jarabo-Amores, P.; Rosa-Zurera, M.; Vicen-Bueno, R.; Nieto-Borge, J.C. (2007). Neural Network Based Approaches for Detecting Signals With Unknown Parameters. Intelligent Signal Processing, 2007. WISP 2007. IEEE International Symposium pp.1-6.

F H Haynie, J P Upham. (1971). Effects of atmospheric pollutants on corrosion behavior of steels. Material Perform, 1971, 10(11):18.

H M G Smets, W F L Bogaerts. (1992). Neural network prediction of stress corrosion cracking. Materials performance, 1992, 31(9):64.

H M G Smets, W F L Bogaerts. (1992). SCC analysis of austenitic stainless steels in chloride-bearing water by neural network techniques. Corrosion, 1992, 48(8):618.

J Leifer, J I Mickalonis. (2000). Prediction of aluminum pitting in natural waters via artificial neural network analysis. Corrosion Science, 2000,56(6):563.

J Leifer, P E Zapp, J I Michalonis. (1999). Predictive models for determination of pitting corrosion versus inhibitor concentrations and temperature for radioactive sludage in carbon steel waste tanks. Corrosion, 1999, 55 (1): 31 .

J. A. Gonzalez, A. Molina, M. L. Escudero, and C. Andrade, (1985). "Errors in the electrochemical evaluation of very small corrosion rates-I. Polarization resistance method applied to corrosion of steel in concrete," J. Corros. Sci., vol. 25, no. 10, pp. 917-930, 1985.

Jianping Cai, Wei Ke. (1997). Predicting the corrosion of steels and low-alloy steels in atmosphere by artificial neural network. Journal of corrosion and protection Sinica. 1997, 17(4): 303. 
Satoshi Kibata, Hisayoshi Matsuyama, and Shigeyuki Tateno. (2009). "Estimation of Corrosion Rates on Outside Surface of Pipes", ICROS-SICE International Joint Conference 2009, Fukuoka International Congress Center, Japan.

Takako Kuroda, Ryuzo Takai, Yuki Kobayashi, Yoshiteru Tanaka and Shoichi Hara. (2008). " Corrosion Rate of Shipwreck Structural Steels under the Sea”, 978-1-4244-2126-8/08,2008 IEEE.

Wei You, Yaxiu Liu. (2008). "Predicting the Corrosion Rates of Steels in Sea Water Using Artificial Neural, Fourth International Conference on Natural Computation, 2008.

Xiaoyan Ma, Yanbing Luan, Zuyu Qu, et al.. (2001). Application of neural network in prediction of corrosion rate of metals in atmosphere. Journal of university of science and technology Beijing. 2001, 23(2): 123.

Y Cheng, W L Huang, C Y Zhou. (1999). Artificial neural network technology for the date processing of on-line corrosion fatigue crack growth monitoring. International Journal of Pressure Vessels and Piping, 1999 $76(2): 113$. 
Table 1. Sample of experimental data

\begin{tabular}{|c|c|c|c|c|}
\hline $\begin{array}{l}\text { Resistivity } \\
\text { Ohm.cm }\end{array}$ & $\begin{array}{l}\text { Impressed current } \\
\text { density, } \mu \mathrm{A} / \mathrm{cm}^{2}\end{array}$ & $\begin{array}{l}\text { Location of anode } \\
\text { from specimen, } \mathrm{cm}\end{array}$ & $\begin{array}{l}\text { Corrosion } \\
\text { current, } \mu \mathrm{A} / \mathrm{cm}^{2}\end{array}$ & $\begin{array}{l}\text { Corrosion } \\
\text { rate, gmd }\end{array}$ \\
\hline \multirow[t]{12}{*}{33.4} & 24.98 & 10 & 7.40 & 1.85 \\
\hline & 15.73 & 10 & 17.30 & 4.32 \\
\hline & 6.47 & 10 & 29.60 & 7.40 \\
\hline & 26.11 & 20 & 7.40 & 1.85 \\
\hline & 16.90 & 20 & 19.70 & 4.93 \\
\hline & 7.60 & 20 & 29.60 & 7.40 \\
\hline & 26.63 & 30 & 9.86 & 2.47 \\
\hline & 17.40 & 30 & 17.27 & 4.30 \\
\hline & 18.10 & 30 & 27.13 & 6.80 \\
\hline & 26.94 & 40 & 7.40 & 1.85 \\
\hline & 17.70 & 40 & 17.30 & 4.30 \\
\hline & 8.40 & 40 & 27.13 & 6.80 \\
\hline \multirow[t]{12}{*}{524.93} & 20.05 & 10 & 4.93 & 1.24 \\
\hline & 10.80 & 10 & 12.3 & 3.08 \\
\hline & 1.55 & 10 & 19.7 & 4.94 \\
\hline & 21.30 & 20 & 4.94 & 1.23 \\
\hline & 12.00 & 20 & 9.87 & 2.46 \\
\hline & 2.80 & 20 & 17.30 & 4.32 \\
\hline & 22.10 & 30 & 4.95 & 1.24 \\
\hline & 12.85 & 30 & 9.90 & 2.47 \\
\hline & 3.60 & 30 & 19.70 & 4.95 \\
\hline & 29.27 & 40 & 7.40 & 1.85 \\
\hline & 13.67 & 40 & 12.40 & 3.00 \\
\hline & 4.43 & 40 & 19.70 & 5.00 \\
\hline \multirow[t]{12}{*}{4807} & 15.93 & 10 & 2.47 & 0.62 \\
\hline & 8.23 & 10 & 7.40 & 1.85 \\
\hline & 0.52 & 10 & 13.30 & 3.10 \\
\hline & 17.79 & 20 & 4.90 & 1.24 \\
\hline & 10.08 & 20 & 7.40 & 1.85 \\
\hline & 2.37 & 20 & 14.80 & 3.70 \\
\hline & 19.74 & 30 & 4.93 & 1.23 \\
\hline & 12.00 & 30 & 9.87 & 2.47 \\
\hline & 4.30 & 30 & 13.40 & 3.09 \\
\hline & 21.50 & 40 & 2.47 & 0.40 \\
\hline & 13.80 & 40 & 7.40 & 1.85 \\
\hline & 6.00 & 40 & 14.80 & 3.70 \\
\hline
\end{tabular}


Table 2. Comparison between Experimental and RBFNN

\begin{tabular}{|l|l|l|l|l|l|}
\hline $\begin{array}{l}\text { Resistivity } \\
\text { Ohm.cm }\end{array}$ & $\begin{array}{l}\text { Impressed current } \\
\text { density, } \mu \mathrm{A} / \mathrm{cm}^{2}\end{array}$ & $\begin{array}{l}\text { Location of anode } \\
\text { from specimen, } \mathrm{cm}\end{array}$ & $\begin{array}{l}\text { Corrosion } \\
\text { current, } \\
\mu \mathrm{A} / \mathrm{cm}^{2}\end{array}$ & $\begin{array}{l}\text { Experimental } \\
\text { Corrosion rate, } \\
\text { gmd }\end{array}$ & $\begin{array}{l}\text { RBFNN Model } \\
\text { Corrosion rate, } \\
\text { gmd }\end{array}$ \\
\hline 33.4 & 6.47 & 10 & 29.60 & 7.40 & 7.28765 \\
\hline 33.4 & 26.11 & 20 & 7.40 & 1.85 & 1.84391 \\
\hline 524.93 & 10.80 & 10 & 12.3 & 3.08 & 3.10024 \\
\hline 524.93 & 21.30 & 20 & 4.94 & 1.23 & 1.27683 \\
\hline 4807 & 19.74 & 30 & 4.93 & 1.25 & 1.31026 \\
\hline 4807 & 13.80 & 40 & 7.40 & 1.85 & 1.87463 \\
\hline
\end{tabular}

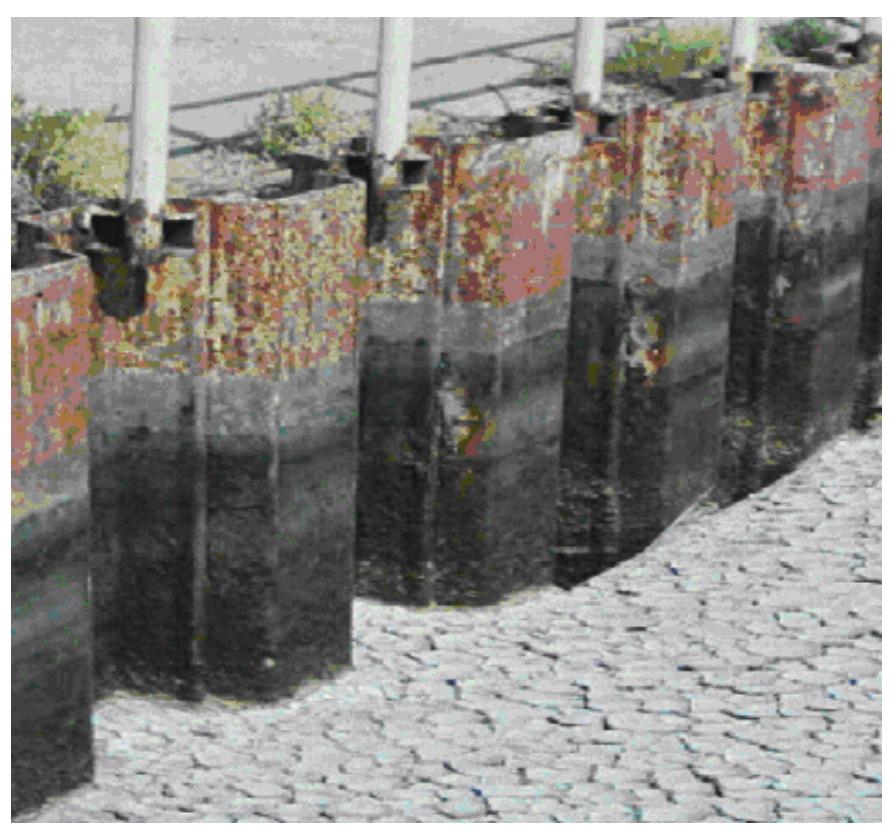

Figure 1. Schematic diagram of the Field apparatus

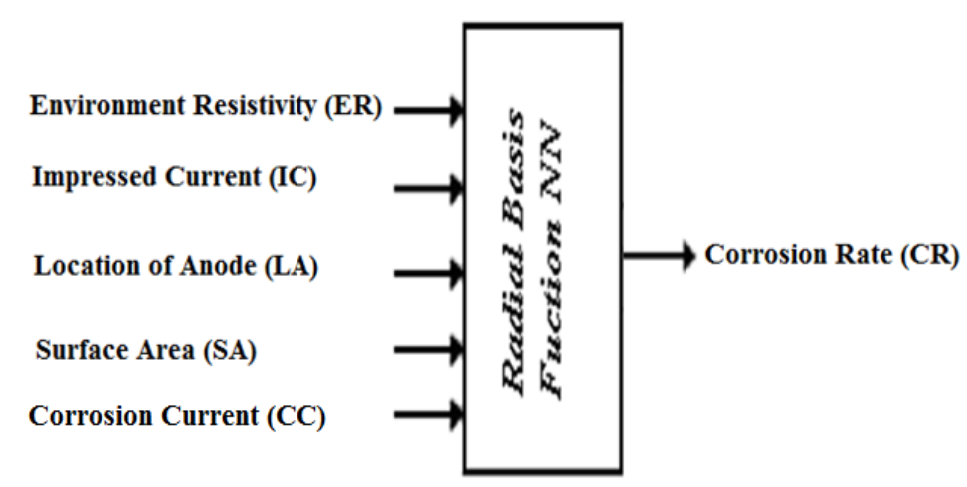

Figure 2. RBFNN Corrosion rate Predication model 


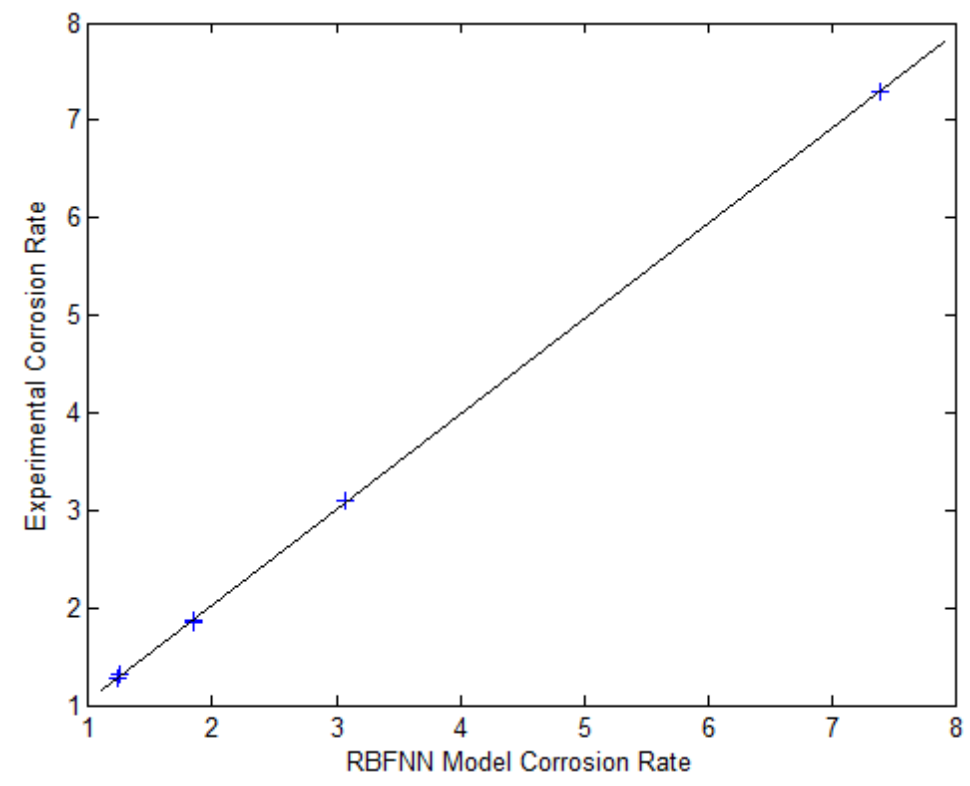

Figure 3. Comparison of RBFNN with the experimental output 